\title{
DISCUSSION - SESSION I
}

Principal discussants: Henry Polach, Australian National University, Doug Harkness, NERC, Donald Sutherland, Placer Analysis Limited

A large part of the early discussion of the session concerned the study samples and the risks of contamination in the samples. A number of specific points arose.

1. Peat and humic samples. No contaminant of widely varying age was observed as present in the samples since the agreement between the peat and humic results is very good. However, some laboratories identified the problem of chlorine in the samples.

2. Wood samples. Some laboratories split the wood samples and treated one part as whole wood while extracting cellulose from the other part. Typical difference was 40 years, well within error. Thus, these data revealed no evidence of significant contamination.

3. Stage 1 carbonate. The yields were low from the acid hydrolysis of these samples, raising the possibility of the presence of clay minerals. The organizers could not explain this, in light of their production method. Radon contamination is also possible. Tight counting schedules may have forced labs to count samples too soon.

The discussants suggested that some observed biases might be due to the nature of the sample, not simply to the counting or pretreatment processes.

Some discussion followed regarding whether or not the treatment given to these samples was any different from routine. The stated policy was to treat the samples routinely, but the tendency might be to give them special treatment. Conversely, in a sense, the sample information provided was not as detailed as might be expected from a routinely submitted sample. The organizers had, in fact sent full details of the samples wherever possible. Participants agreed that the samples in Stage 3 were as representative as possible of the samples which a lab might typically receive. 